Annallee Q. Aron, 2020

Volume 6 Issue 1, pp. 236-253

Date of Publication: $06^{\text {th }}$ April 2020

DOI- https://doi.org/10.20319/pijss.2020.61.236253

This paper can be cited as: Aron, A. Q., (2020). Dynamics of Community of Learning (Col) Discourse on Employing Stem Activity in Conducting Research Project. PEOPLE: International Journal of Social Sciences, 6(1), 236-253.

This work is licensed under the Creative Commons Attribution-Non Commercial 4.0 International License. To view a copy of this license, visit http://creativecommons.org/licenses/by-nc/4.0/ or send a letter to Creative Commons, PO Box 1866, Mountain View, CA 94042, USA.

\title{
DYNAMICS OF COMMUNITY OF LEARNING (CoL) DISCOURSE ON EMPLOYING STEM ACTIVITY IN CONDUCTING RESEARCH PROJECT
}

\author{
Annallee Q. Aron \\ Mindanao State University Iligan Institute of Technology, Iligan City, Philippines
}

annallee.aron@deped.gov.ph

\begin{abstract}
In 1995, Science Education Institute (SEI) has made the biggest revolution ever in the history of Philippine Education by guiding the Department of Education Culture and Sports (DECS) to mold young citizens who are scientifically and technologically inclined into the greatest manpower that will provide social and economic growth in the country. Part of this revolution is offering special science class with a curriculum packed with more science, mathematics, and scientific research as subjects compared to the basic education curriculum. This curriculum has been implemented in 2 decades and yet in the latest Department of Science and Technology, DOST survey in a rating of 1-7 experts gave Philippines an average score of 3.72 in terms of our global competitiveness in the world of scientific research and technology. There is the need to further revolutionized and explore not only the curriculum but also the approach of teaching scientific research especially for young scientist enthusiasts who wants to develop the skills in conducting Science Research. This study is conducted to capture the dynamics of the online discourse by analyzing the question \& interaction pattern and response among the CoL (with the presence of the more-knowledgeable-others) using the Online google classroom STEM lesson
\end{abstract}


version on developing a quality research investigatory projects and in changing the students' self-efficacy on conducting a science research project. The captured dynamics will provide us a theory and model with a panoramic view of handling the future classes in conducting a science investigatory project in all science research curriculums.

\section{Keywords}

Social Learning, STEM Activity, Research Project, Teaching Approach

\section{Introduction}

\subsection{History in Education}

The first attempt to revolutionize the Science and Technology in the Philippine happened way back 1993 through the implementation of Engineering and Science Education Program (ESEP) now known as Science, Technology and Engineering (STE) with a formulated curriculum that develops the scientific and engineering skills of learners under the leadership of Science Education Institute (SEI) in their Science and Technology Plan (STEP) 2000. The initiative of SEI was made possible in collaboration with the Department of Education and Sports (DECS), the University of the Philippines System (UP) and the Regional Science Teaching Centers (RSTCs) and in consultation with the National Economic Development Authority (NEDA) conceptualized this plan called Science and Technology Education Plan (STEP) guided by the following objectives to develop a scientifically and technologically literate citizenry and accelerate the development. Creating more S \& T manpower needed for social and economic growth projected last 1994 to 1998. (SEI-AR1993.pdf, 1993)

The granted $110 \mathrm{~S} \& \mathrm{~T}$ schools that offer Special Science Classes (SSC) uses Engineering and Science Education Program (ESEP) continue to operate up to this date under the independent operation of the Department of Education (DepEd) issuing series of orders: Deped Order No. 62, s. 1996; DepEd Order 55 s. 2010; DepEd Order No 104 s. 2010, and DO 20, s. 2015. The orders has been observed since there is no new issuance that supersede the orders. This special science curriculum apart from the Junior High's Enhanced Basic Education Curriculum offers science research as a subject that prepares them to be scientifically and technologically ready as a student in the Senior High Science, Engineering and Technology (STEM) Curriculum under the Academic track of K-12 Program newly implemented by the Department of Education in year 2016 stipulated in the DepEd order no. 43, s. 2013, DepEd Order No. 19, s. 2016 and Republic Act 10533 of 2013. 
More than two decades, the $110 \mathrm{~S} \& \mathrm{~T}$ high schools have been implemented, the need to enhance Science and Technology to the citizenry especially to people who are scientifically inclined, still exists up to this day. Philippines as a country needs to catch up, to be at par with other countries, especially in Science and Technology. For this reason the continuing growth in this respect, must be to strengthen, the learners' research skills.

Sadly, our country have been having a struggling performance in Scientific research and it is mentioned in the latest Department of Science and Technology, DOST (2012) sponsored survey, asking experts to rank the country from 1 to 7 on the Global competitiveness of the Philippines under the pillar of innovations especially in scientific and technology research were given an average rank of 3.72 can be an indication of poor performance globally.

Philippine education has a lot of tasks to be able to cope with the global competitiveness in terms of innovation, a needed attention and changes must be done especially in the area of conducting scientific researches. Study the dynamic of involving a community of learners might bring change in the instruction of teaching research subjects and enhance the quality of Science research projects as well.

Since then, from the first implantation, Filipino science research teachers on the ground have been implementing the curriculum for 20 decades but uses varied teaching approaches/Pedagogy and sometimes uses a disorganized teaching approaches to pass-on the needed research skills to scientifically inclined learners. The Authorities have set the curriculum that guided teachers 'what to teach' but no definite teaching approaches/pedagogy were given as to 'how to teach' research as the subject.

As of now, with the newly implemented K-12 beginning in the year 2013 from K-10 the official learning resource portal: https://lrmds.deped.gov.ph have created plenty of quality learning resource materials for all grade levels. However, due to its vast responsibilities of providing DepEd teachers with the needed resource materials, some competencies and curriculum standards including the Research Subject for Special Science Curriculum, Practical Research 2 and Capstone Project for grade 11 have no learning materials yet available in this portal.

Despite that there were many studies conducted on the effect of learning with the combination of one of any of the following variables: parental involvement Wiygul, S.M., \& Gifford V.D. (1992) but the combinations of all these variables including the presence of the 
scientists with the online google classroom as a platform of communication between these CoL (the more knowledgeable others by Vygotsky and the community of practice by Wenger Social Learning Theory) have not given any attention in the field of research especially in the instruction of conducting research project.

Capturing the dynamics involve between the conversations of learners and the Community of Learners as the more- knowledgeable-others through doing a task, asking questions and responding to each other in an online and offline classroom on conducting Research Project using STEM lesson as a medium of instruction can generate a theory and model on how future scientific research teachers in the special science curriculum can manage toward changing the students' self-efficacy on conducting a research project and achieving the best quality as well.

\subsection{STEM Lessons}

STEM lessons are interdisciplinary teaching approaches of Science, Technology, Engineering and Mathematics (Sutaphan \& Yuenyong, 2019) is by nature and composition is somewhat similar to conducting a research project. It allows learners to collaborate and have an opportunity to take part on solving real world problems such as social issues and/ or human needs such as disasters, pollutions, environmental issues, biotechnology, health, cosmetics, ecosystems, energy, market, comers, and designing some technological products. STEM lesson is comprised with 7 stages which led learners to the integration of science, technology and mathematics concepts, be exposed in the -world problem and work as a team. STEM lesson focusses more on the processes, it abides within the curriculum standards that encourages learners to observe project and problem based approach. The STEM process is itself fitting to conducting a research project especially to learners of the Junior High Special Science. The hands on activity of the STEM lesson is context-based with the following seven (7) Stages: (1) Identification, (2) Identification of potential solution, (3) Need for knowledge, (4) Decisionmaking (5) Development of protype or product, (6) Test and Evaluation of the solution and (7) Socialization and completion decision stage (Theerasan \& Yuenyong, 2019).

\subsection{Cognitive Level on Learners' Generated Questions/Response}

A study of Perkins \& Murphy (2006) proves the effectivity of Online Asynchronous Discussion (OAD) on identifying and measuring individuals' critical thinking. Assaly and Smadi (2015) was able to evaluate the cognitive levels from the generated questions following the 
reading of text through the usage of a checklist based Bloom's Taxonomy. Chu, Li, \& Hsia as cited in $\mathrm{Hu}$ and Chiou (2012) explained that online environment may have advantages for promoting student environment with more opportunities to think, ask, and answer questions. Kaya (2017) classified questions into three types: (1) information that requires recall questions as short answers and coded as low-level questions, (2) the open-ended questions that requires several sentences and student's reasoning were coded as high-level questions and lastly, the questions that calls for clarifications of direction as the learners interact in the classroom activities were coded as task-oriented-questions. On the other hand the student response in relation to teacher questioning was included in the study of Kim (2015) which consisted of higher-order thinking and lower-order thinking. Under the higher order thinking category were three sub-types: (1) explanation responses (E), (2) self-evaluation of reasoning responses (SE), and (3) self-evaluation of others' reasoning responses (SEO). Under the lower-order category, there was one sub-type: simple responses $(\mathrm{S})$.

\subsection{Influence of Research Project to Learners}

Research is important to every learner, the process of conducting research is the foundation of science and it provides the evidence that is needed to formulate and support the answers to many vital questions. By carrying out a research one will develop the analytical skills that are helpful to solve problems encountered daily (Stewart et al., 2009, p. vii). It allows students to work cooperatively on activities and make decisions about how to proceed rather of the steps, including how to calculate the answer. Students talk with each other and defend their ideas. For learning to occur, students need to be engaged in topics not just in the standards but also inherently interesting to the students (Luft \& Roehrig, 2004).

Conducting a science research project has been a requirement for students enrolled in enrolled in the Special Science Class. Students encountered difficulty on coming up with a quality science research project. The difficulty may depend on the students' science self-efficacy and lack of resources such as human (science teacher, scientists \& parental support). The origin of difficulty has never been determined and addressed despite the evolution of many teaching approaches.

\subsection{Community of Learning (CoL)}

The learners' cognitive development rely on some level of assistance provided by the more knowledgeable others- be it a teacher or a scientist. Failure to give necessary assistance to 
acquire knowledge may hinder them to overcome the challenges ahead for them to become ready and independent as learners. They need to perform the tasks repeatedly with guidance and constant mentoring of the Community of Learning (CoL) as characterized in the Wenger Social Learning Theory (Wenger et al., 2016) until they are able to see themselves as self-efficient in their area of interest. As of now, the learning community has not been fully implemented although it is stipulated in the new DepED curriculum standards as one of the learning competencies, encouraging schools to create a Memorandum of Agreement (MOA) with universities having resident scientists.

Teachers with the limited technical laboratory skills cannot play the role as the more knowledgeable others. The learners are left with no one to accommodate their curiosity, no one to answer their queries and they will become hopeless to acquire the needed knowledge.

\subsection{Technology as the Learning Venue}

The evolution of technology, especially the online social media applications brought so much change in the way learners acquire knowledge. It has been widely used by many educators of today because of its convenience on communicating with the digital learners. The online social media applications can be a platform to bring the more knowledgeable or more capable others to the learners. This online platform would be a comfortable zone for learners to anytime throw their questions between their group mates, parents, and teachers and even to the scientists. The tight schedule of the competent others will not be any more a hindrance to assist the learners especially in conducting a Research Project - that provides learners an opportunity to experience, understand, and share scientific phenomena both in written and verbal medium.

This study is conducted to capture the dynamics of the online and offline discourses by analyzing the question \& interaction pattern revised by Erdogan \& Campbell (2008) and response (Kim, 2015) among the CoL (with the presence of the more-knowledgeableothers/experts) using the STEM lesson in the Online google classroom version on developing a quality research projects and in changing the students' self-efficacy on conducting a research project. The captured dynamics will provide us a theory and model with a panoramic view of handling the future classes in conducting a research project in all science research curriculum.

Local and Global competitiveness are the ultimate motivation of the implementation of the K-12 Curriculum, this calls for the development of the primary scientific skills needed especially in the field of Science, Engineering and Technology (STEM). The search for a better 
way to promote scientific research atmosphere is valuable not only to individuals who are incline in science but as a country in holistic sense. The result of this study would ultimately benefit the learners to come up with quality research projects.

This is an exploratory study that investigates on the questioning and interaction patterns of the online and offline community of learners $(\mathrm{CoL})$ using STEM activity on conducting a research project. Its primary mechanism is more on motivating the learners to be involved in solving social issues and the opportunity to take part on suggesting possible solutions to the perennial problems faced by people all over the world particularly in solid waste management research project. There will be nine (9) research project STEM activity to choose from by the participants: A. Biodegradable Plastic; B. Leachate Treatments; C. Recycling Technology; D. Solid Composting (anaerobic digestion, AD)/Biocomposting into biogas/Vermicomposting; E. Waste segregator machine/robots; F. Waste grinding machine; G. Bio-indicator of water waste; H. Phytoremediation of leachate; I. Water analysis of runoff leachate.

The designed learning activities allow the facilitation of teachers to encourage learners to ask more types of questions: Lower Cognitive Questions (LCQ), Higher Cognitive Questions (HCQ) and Task-oriented Questions (TOQ). In addition, the learners is free to respond in different manners such as explanation response (E), self-evaluation response (SE), selfevaluation of others' reasoning response (SEO) with this STEM learning activities. The origin of this classification of questioning is patterned from bloom's taxonomy to promote higher forms of learning that includes evaluating, analyzing, applying and understanding not just rote memorization like remembering. This bloom's taxonomy of learning outcomes evolves with time and much modification are now currently established in this new educational pedagogies that is more of a learner centered rather a teacher centered one. Creativity is now classified as being the highest form of bloom's taxonomy of learning outcomes and the perfect avenue to foster creativity especially to Science, Technology, Engineering, and Mathematics enthusiasts is to expose them with scientific researches. Schemes for analyzing the qualitative characteristics of questions have been proposed by many researchers but the present study adopted GraesserPerson-Huber (GPH) scheme. The figure 1 shows the conceptual framework on how the study will further be done. 


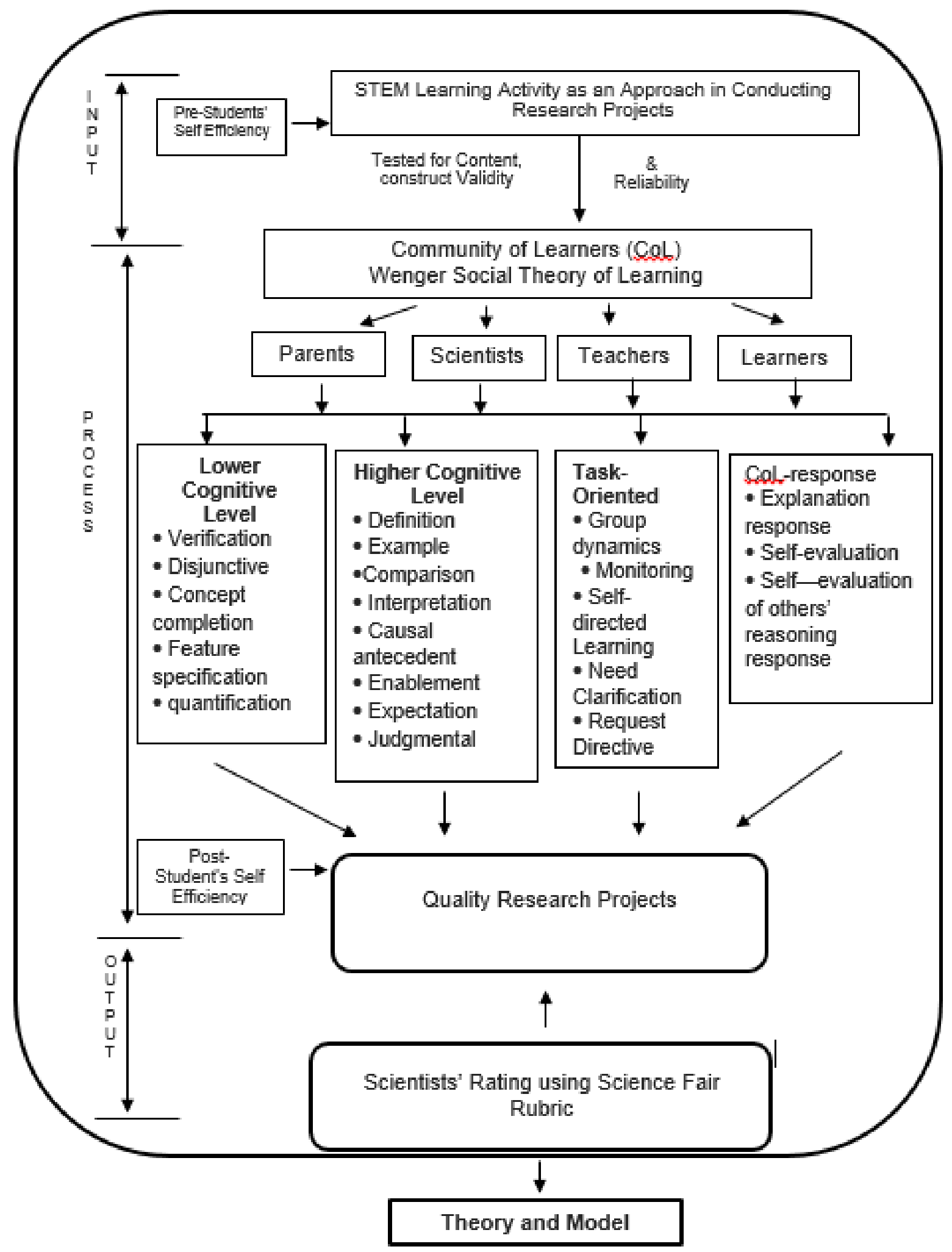

Figure 1: Synopsis of the Research Paradigm 


\section{Methodology}

\subsection{Research Design}

The study is exploratory in nature that involved both the qualitative and the quantitative approaches. The qualitative part uses content analysis of the discourses among the CoL (parents, scientists, teacher, and students) and the Quasi-Experimental design is the quantitative part that investigates the CoL's dynamics (through question schemes) when a STEM lesson is used as an approach to come up with a quality Research Project.

\subsection{Selection of the Subject and the Study Area}

There are two schools offering Special Curricular Program in Science, Technology and Engineering (formerly ESEP) in Iligan City, the Iligan City National High School (ICNHS) and the Iligan City East High School (ICEHS). Both of these schools are part of this study. Outside participants such as the scientists having the criteria of being an expert and possessing a great laboratory skills due to his/her experience especially in facilitating research projects. Parents, also plays as a participant in this study to determine their influence in the dynamics of fostering quality research projects. Only one parent/guardian or any adult household member for each child shall participate.

For ethical considerations, proper protocol will be observed which include permission to conduct the study from the School Principal, Assistant School Principal, Department head of Senior High Schools, and the Department of Education Schools Division Superintendents (SDS) of Iligan City, Lanao del Norte. Includes in the subject of the study are the students of grade 10 enrolled in the Special Science Class (SSC) in Iligan City for the year SY 2019-2020.

\subsection{Selection of Learning Activity}

The topic selected to engage in a STEM learning activities on science research project is about one of the most perennial problems globally that is Waste Disposal with the following researchable areas of study: Biodegradable plastic, Leachate Treatments, Recycling Technology, Solid Composting (anerobic digestion, Biocomposting into biogas/vermicomposting, Waste segregator machine/robots, Waste grinding machine, Bio-indicator of water waste, phytoremediation of leachate, and water analysis of runoff leachate. Learners as a group can choose one area of study as research project. The STEM learning activity infused with conducting a research project will undergo a content validation assessed by experts and construct validity measured using Exploratory Factor Analysis (EFA). The reliability of the STEM activity 
is measured using inte-rating of nonprint material evaluation sheet which is measured by using the alpha coefficient reliability.

\subsection{The Instrument}

This research uses google classroom apps, self-efficacy questionnaire, taxonomy of Question Types, STEM lesson Plan, and DepEd's Science Research Project Evaluation sheet.

\subsubsection{Google Classroom}

Google classroom apps allows participants to communicate with one another, view and edit presentations or documents, view videos, interact with other participants by exchanging comments, and engage with resources in work groups. Participants stay connected wherever, uniting learners, parents, teachers and Scientists quickly without space and time constraints. Teachers and Experts common problems on engaging and preparing lessons lies on the availability of time (Angeles \& Matsuura, 2019). There are so many barriers, local teachers, even faced their own difficulties in conducting their own personal research project (Omar et al., 2019). This google classroom can solve one of the barriers faced in conducting research. It can provide an easy access for teachers/experts to revisit learners' research projects. Learners can collaborate with peers easily and revise their work frequently knowing that someone else will view or comment on their work. Parents, Teachers, and scientists/experts will be the knowledgeable others that can supply immediate feedback for learners regarding their research project.

\subsubsection{Parent in Google Classroom}

To elicit the parent's participation and to account for their presence they will join the google classroom using their gmail account. The teacher will ask for the parent's gmail account and enroll them in the google classroom through sending an invitation. When the parents received the google classroom invitation notification they will then accept and automatically able to join the classroom. Their participation will be elemental in the 4th (decision makings) and 5th stages (development of the product) of the STEM activity.

\subsubsection{Scientists in Google Classroom}

The mentoring of the scientists/experts with the suited expertise on following researchable areas of study within waste disposal: Biodegradable plastic, Leachate Treatments, Recycling Technology, Solid Composting (anerobic digestion, Biocomposting into biogas/vermicomposting, Waste segregator machine/robots, Waste grinding machine, Bioindicator of water waste, phytoremediation of leachate, and water analysis of runoff leachate. 
There are 4 scientists/experts involve to mentor the students in this study. The chosen scientists/experts are represented with the following expertise as chemist, chemical engineer, experienced research adviser in robotics and a teacher in statistics. Qualitative data will be generated from the way they post their online questions in the Google classroom apps as well as their responses to the learners' questions. Offline data will also be collected during the one (1) day Symposium of the Scientists/Experts with the learners through audio and video recording. Scientists participates in the mentoring on the 3rd (need for knowledge), 4th stage (decision makings), 5th stage (development of the product), 6th stage (Test and Evaluation, up to the 7th stage (Socialization and Completion), the last stage of the STEM Activity. However, Scientists/Experts do not take part in the mentoring process of learners in the first stages: 1st (Identification of social issues) and 2nd (Identification of Potential Solutions)

Self-efficiency on assisting a research project will also be administered before and after conducting the research study adopted from Self-Efficacy in Research Measure (Philips \& Russell, 1994).

At the last stage of the research, the learners shares their science research project, a rubric to evaluate the quality as instrument will be used by the invited scientists to assess the quality of the students' project.

\subsubsection{Teacher in Google Classroom}

The teachers (not the researcher) will utilized the google classroom STEM learning activities patterned from Sutaphan \& Yuenyong (2019) that includes 7 stages : (1) Identification, (2) Identification of potential solution, (3) Need for knowledge, (4) Decision-making (5) Development of prototype or product, (6) Test and Evaluation of the solution and (7) Socialization and completion decision stage. This STEM learning activity is somewhat similar in procedure as in conducting a research project. A STEM learning activity, Self-efficiency on assisting a research project adopted from Self-Efficacy in Research Measure (Philips \& Russell, 1994) will also be administered before and after conducting the research study.

\subsubsection{Learners in Google Classroom}

The learners will be guided by the STEM learning activities patterned from Sutaphan \& Yuenyong (2019) with the parents, scientist, and teachers as mentors to assist them online on conducting a research project. Each conversations either in question form or a sort of studentresponse from either the parent, scientist, teacher or within learners posted in Google classroom 
apps will be analyzed using the Taxonomy of question type instrument adopted from Graesser and Persons (1994) revised by Erdogan and Campbell (2008) and CoL-response instrument adopted from the study of Kim (2015). The research project as product will be presented during the science fair 2019 and will be judge as to the quality using a rubric. The Self-efficiency before and after will also be administered in this research.

\subsubsection{Self-Efficacy Questionnaire}

This instrument Self-Efficacy in Research Measure (Philips \& Russell, 1994) will be adopted to be able to determine whether the presence of the knowledgeable others $(\mathrm{CoL})$ has in some way help boost the confidence of the learners. A written permission was given by the author, the instrument are freely available for use especially to students and members in the sscientific community.

\subsection{Online/Offline Discourses}

Google Classroom discourses while following the STEM lesson will be the avenue to generate conversation among the CoL by posting of messages, sharing files and links. These will serve as the primary data that will lead the researcher to determine the dynamics involve needed to have quality research project classifying each through the instrument taxonomy of question type adopted from Graesser and Persons (1994) revised by Erdogan and Campell (2008) and CoL response instrument adopted from the study of Kim (2015). There will be Online through online threads and Offline Discourses through one (1) day symposium with the scientists/experts that will be collected. Video and Audio taping the symposium is the technology that will be used to keep record of the discourse.

Validity of raters' judgments in coding the online discourses of the participants is a mustconsideration of the researcher. Each taxonomy of question type and participant-responses will be assigned with a permanent code consisted all throughout the study. It will be read several times before assigning a code with respect to what question type or response would the question or responses posted by each of the participant in the social media platform. The researcher and two outside members who are masteral and doctorate teachers were enlisted to analyze and code the CoLs' online discourses. This is called inter-rater reliability or inter rater agreement. It refers to the degree of agreement among raters who rate the same item, scale, or instrument. It shows how homogeneous, or in consensus the ratings as given by the raters. 
The inter-raters will be oriented on what and how to go about the rating of the transcripts using the pre-set predictors. To increase homogeneity of ratings, feedback from raters especially where judgment varies on some items will be discussed. A consensus on the rules for rating items will must be observed. The percentage inter-rating agreement and percent reliability will be computed with the formula:

Inter-rating agreement equation

Average of Total agreed items $=($ Number of agreed items of rater $1+$ Number of agreed items of rater 2$) / 2$

$\%$ reliability $=($ Total No. of disagreed itmes/ average of total agreed items $)$ X $100 \%$

\subsection{STEM Lesson Plan}

In this research the stream line of creating a STEM lesson plan patterned from Suthaphan \& Yuenyong (2019) - that begins with by exposing learners with some pressing social issues and allows them to creatively generate possible solutions is use as an approach in coming up with quality Research Project.

This STEM lesson will be uploaded in the google classroom apps is designed with 7 stages that facilitate discourses among the CoL. Learners will be given a tasks in each of the seven (7) stages: (1) Identification of social issues, (2) Identification of potential solution, (3) Need for knowledge, (4) Decision-making, (5) Development of prototype or product, (6) Test and evaluation of the solution and (7) Socialization and completion/ decision stage. The task in the STEM lesson plan should carefully be designed such that it will encourage each participants to converse or post messages (either questions, tasks related, or responses). The researcher have chosen A STEM lesson activity on waste garbage disposal management as the social issue/real world problem. In this STEM lesson activity the learners will do a research project on either of the following solutions of the waste disposal managements: A. Biodegradable Plastic; B. Leachate Treatments; C. Recycling Technology; D. Solid Composting (anaerobic digestions, AD)/Biocomposting into biogas/Vermicomposting; E. Waste Segregator machine/robots; F. Waste grinding machine; G. Bio-indicator of water waste; H. Phytoremediation of Leachate; and I. Water analysis of runoff leachate.

\subsection{Coding and Documentation}

Coding is the most laborious of any part in the qualitative research. It will requires patience, concentration, focus and good judgment to sort the items found in the online discourses 
between the CoL. The audio transcribed discourses and the posted exchanges of conversations between the experts, parents, research teacher and the learners will be coded according to the types of questions: Lower Cognitive Questions (LCQ), Higher Cognitive Questions (HCQ) and Task-oriented Questions (TOQ). In addition, learners' respond in different manners such as explanation response (E), self-evaluation response (SE), self-evaluation of others' reasoning response (SEO) are also coded to capture the dynamics of the converstation.

The highest number of occurrences from the extracted data will provide a baseline information for the patterns of discourses in conducting a research project with the Google classroom STEM learning activity as a tool in facilitating learning, these will then be, the bases for the formation of grounded theory and Model to emulate such that quality of Research Projects will be assured. A sample of the analysis of the discourses taken from the taxonomy of question type by Graesser \& Person (1994) revised by Erdogan and Campbell (2008).

The 1st type of predictors: preset predictor and some predictors may be discarded due to non-occurrence. The second predictor is the emergent predictors, a text seen several times in the discourses between CoL but are not found in the preset of predictors. Two documentations will be done Online using the google classroom threads and the Offline through video and audio taping during the symposium that will be given by the scientists/experts to the learners.

\subsection{Data-Gathering, Data Collection and Data Analyses}

Data-gathering involved Six phases: the first(1st) phase is the handling of classes by the teacher and learners with the introduction of the STEM learning activity on conducting a research project published in google classroom (privately accessible to CoL). There will be an orientation and enrollment of grade 8 Special Science Class (SSC) students SY 2019-2020 to google classroom that serves as the avenue in facilitating the STEM lesson in the presence of their parents, invited scientists/experts, their own teacher and their own group mates towards creating a quality research project. The presence of the researcher will also be introduced as form of immersion. This will make learners to become comfortable with the presence of the researcher.

The second (2nd) phase will be the self-efficacy test before the online discourses proper. This data will be used to determine whether the self-efficacy before the presence of the knowledgeable others $(\mathrm{CoL})$ with STEM lesson as an approach will affect the quality of the research project. 
The third (3rd) phase will be the offline discourses through research project symposium with the scientists/experts as the speakers that will enrich the learners with the recent researches in solid waste management, robotics and statistics.

The Fourth (4th) phase will be the online discourses in the google classroom with exchanges of comments, questions, file sharing, experiences while planning on how to come up with a research project in any of the following real world problem on waste disposal management: A. Biodegradable Plastic; B. Leachate Treatments; C. Recycling Technology; D. Solid Composting (anaerobic digestion, AD)/Biocomposting into biogas/Vermicomposting; E. Waste segregator machine/robots; F. Waste grinding machine; G. Bio-indicator of water waste; H. Phytoremediation of leachate; I. Water analysis of runoff leachate.

All discourses will be extracted for identification of what taxonomy of question type and what participant-response category.

The patterns of the discourses will be determined manually and cross checking through "word search" application to sort recurring themes. The taxonomy of question type and participant-responses in relation the STEM learning activities in conducting a research project will be determined using the preset themes or predictors. However, emergent themes which will recur and are not found in the pre-set predictors will be considered. Voluminous data are expected and to prevent spreading of results, some data will be eliminated and the most recurring themes will be considered. To observe uniformity and to prevent bias in the interpretation of data, two inter-raters or evaluators will evaluate, identify, and categorize the data based on the pre-set themes.

Cross-validation technique Cross-validation is important in a qualitative study (Patton, 1989). Triagulation of data will be used as the main cross-validation technique. Triagulation is the process of validating the claims highlighted in the study (Olsen, 2004). The online discourse will be match with the interview or a questionnaire about the experience of conducting the Research Project. If these set of data will give consistent result, triangulation was achieved. In particular, triangulation refers to the application and combination of several research methodologies in the study of the same phenomenon (Carugi et al., 2016). Making use of varied observers, several methods of gathering data, theories, and valid instruments then the weaknesses of the will be avoided. The consistency of data that will be obtained from the transcripts of 
classroom discourses will be qualitatively checked with various data obtained from the online discourses and laboratory experiment discourses.

The fourth phase will be the sharing of the research project in front of the Scientific Review Committee (SRC) as an entry in the division science fair. Rubric will be used along with the comments of the SRC to assess the quality of the Research Project.

The fifth phase will be the self-efficacy after the implementation of the STEM lesson as an approach in creating Research Project in Google Classroom Community of Learning (CoL). This phase will determine whether the new procedure of guiding the students in coming up with a quality research project affects their self-efficacy.

\subsection{Statistical Tools}

Descriptive statistical tools such as frequency, percentage, mean and standard deviation, and $t$ test for correlated groups will be used in this study. The use of tables and graphs will ease the interpretation and writ-up of the result.

\section{Conclusions}

The efforts of educating a child is not solely taken by the learner alone but the involvement of the surrounding community. The presence of the experts, peers, teachers, and parents in a google classroom with infused STEM learning activity as a teaching approach will give a sound impact on the learning of the child especially in the line of conducting scientific research.

\section{References}

Angeles, D., \& Matsuura, T. (2019). Successes and Challenges in Lesson Study of Science Teachers in Fukuyama City , Japan. PUPIL: International Journal of Teaching, Education and Learning, December. https://doi.org/10.20319/pijtel.2019.33.206215

Assaly, I. R., \& Smadi, O. M. (2015). Using bloom's taxonomy to evaluate the cognitive levels of master class textbook's questions. English Language Teaching, 8(5), 100-110. https://doi.org/10.5539/elt.v8n5p100

Carugi, C., Facility, G. E., \& States, U. (2016). Methodological Note on Triangulation Analysis in Country Portfolio Evaluations. March. https://doi.org/10.13140/RG.2.1.4234.1526

DOST. (2012). Science and Technology Competitiveness Rankings of the Philippines. October 
2016.

Erdogan, I., \& Campbell, T. (2008). Teacher Questioning and Interaction Patterns in Classrooms Facilitated with Differing Levels of Constructivist Teaching Practices Teacher Questioning and Interaction Patterns in Classrooms Facilitated with Differing Levels of Constructivist Teaching Pract. November. https://doi.org/10.1080/09500690701587028

Gifford, V., \& Wiygul, S. (1992). The Effect of the Use of Outside Facilities and Resources on Success in Secondary School Science Fairs. School Science and Mathematics, 92(3), 3. https://doi.org/10.1111/j.1949-8594.1992.tb12155.x

Hu, H. W., \& Chiou, G. F. (2012). The types, frequency and quality of elementary pupils' questions in an online environment. Turkish Online Journal of Educational Technology, 11(4), 325-335.

Kaya, S., \& Ceviz, A. E. (2017). Pre-Service Teachers' Use of Dynamic Discourse Variables during Classroom Teaching. Journal of Education and Practice, 8(12), 82-89. http://proxy.library.vcu.edu/login?url=https://search.proquest.com/docview/1913349805? accountid=14780\%0Ahttp://vcu-almaprimo.hosted.exlibrisgroup.com/openurl/VCU/vcu_services_page?url_ver=Z39.882004\&rft_val_fmt=info:ofi/fmt:kev:mtx:journal\&genre=article

Kim, S. (2015). An analysis of teacher question types in inquiry- based classroom and traditional classroom settings. IOWA Research Online.

Luft, J., \& Roehrig, G. (2004). Inquiry Teaching in High School Chemistry Classrooms: The Role of Knowledge and Beliefs. Journal of Chemical Education, 81(10), 1510. https://doi.org/10.1021/ed081p1510

Olsen, W. (2004). Triangulation in Social Research: Qualitative and Quantitative Methods Can Really Be Mixed. 1-30. https://www.federica.eu/users/9/docs/amaturo-39571-01Triangulation.pdf

Omar, H. Q., Rustico, J. Y., \& Langam, H. L. (2019). Research barriers of public school teachers of the division of Iligan City. PUPIL: International Journal of Teaching, Education and Learning, April. https://doi.org/10.20319/pijtel.2019.31.189204

Patton, M. Q. (1989). A context and boundaries for a theory-driven approach to validity. 12(4), 375-377. https://doi.org/10.1016/0149-7189(89)90054-2 
Perkins, C., \& Murphy, E. (2006). Identifying and measuring individual engagement in critical thinking in online discussions: An exploratory case study. Educational Technology and Society, 9(1), 298-307.

Philips, J., \& Russell, R. (1994). Research self-efficacy, the research training environment, and research productivity among graduate students in counseling psychology. The Counseling Psycologist, ss, 628-641. https://doi.org/10.1177/0011000094224008

SEI-AR1993.pdf. (1993). http://www.sei.dost.gov.ph/images/ts/SEI-AR1993.pdf

Stewart, A., Bowman, K., Buckley, S., Graves, M., Landis, C., Patterson, N., Rivera, Y., \& Werner, N. (2009). Research Guide for A Students and Teachers. https://www.esf.edu/oelo/sciencecorps/documents/ResearchGuide_NSFGK12.pdf

Sutaphan, S., \& Yuenyong, C. (2019). STEM Education Teaching approach: Inquiry from the Context Based STEM Education Teaching approach : Inquiry from the Context Based. https://doi.org/10.1088/1742-6596/1340/1/012003

Theerasan, C., \& Yuenyong, C. (2019). Developing the floating restaurant STEM education learning for Thai secondary school students. 03002. https://doi.org/10.1063/1.5094021

Wenger, E., Farnsworth, V., Farnsworth, V., Kleanthous, I., Wenger-trayner, E., Farnsworth, V., Kleanthous, I., \& Wenger-trayner, E. (2016). Communities of Practice as a Social Theory of Learning : a Conversation with Communities of Practice as a Social Theory of Learning : a Conversation with Etienne Wenger. April. https://doi.org/10.1080/00071005.2015.1133799 